\title{
ANÁLISIS DE LAS EXPORTACIONES DE HONDURAS UTILIZANDO LA METODOLOGÍA CAN
}

ISSN 2219-6722

ISSNE 2222-2707

José Bayardo Cabrera Rosales, Universidad Nacional Autónoma de Honduras (UNAH), Facultad de Ciencias Económicas, Administrativas y Contables (FCEAC), Instituto de Investigaciones Económicas y Sociales (IIES), Ciudad universitaria, edificio C2, primer piso, Tel/fax: (504) 2239-1849

jcabrera@iies-unah.org

María Auxiliadora López Méndez, Universidad Nacional Autónoma de Honduras (UNAH), Facultad de Ciencias Económicas, Administrativas y Contables (FCEAC), Instituto de Investigaciones Económicas y Sociales (IIES), Ciudad universitaria, edificio C2, primer piso, Tel/fax: (504) 2239-1849

mlopez@iies-unah.org

\section{RESUMEN}

El presente documento analiza la competitividad de las exportaciones de Honduras hacia el Estados Unidos, Europa Occidental y Mercado Común Centro Americano (MCCA). A su vez el documento se divide en cinco secciones; la primera sección describe brevemente diversas teorías del comercio internacional así como algunas maneras de medir la competitividad internacional en materia de exportaciones de las naciones. La segunda sección explica la metodología del Competitive Analysis of Nations (CAN), el software TradeCAN 2012 y el software MagicPlus. La tercera, cuarta y quinta sección describe y analiza las exportaciones desde la perspectiva CAN de los diez principales productos exportados por Honduras hacia los mercados mencionados en el periodo 19902010 a excepción de Estados Unidos donde el periodo se expande hasta el año 2012, determinando la tipología competitiva (Estrella Naciente, Estrella Menguante, Retirada, Oportunidad Perdida) de dichas mercancías en los diferentes periodos de análisis.

Palabras claves: CAN, Exportaciones, Estrella Naciente, Estrella Menguante, Retirada, Oportunidad Perdida. 


\title{
ANALYSIS OF EXPORTS OF HONDURAS USING THE METHOD CAN
}

\author{
ISSN 2219-6722 \\ ISSNE 2222-2707 \\ José Bayardo Cabrera Rosales, Universidad Nacional Autónoma de Honduras (UNAH), \\ Facultad de Ciencias Económicas, Administrativas y Contables (FCEAC), \\ Instituto de Investigaciones Económicas y Sociales (IIES), \\ Ciudad universitaria, edificio C2, primer piso, Tel/fax: (504) 2239-1849 \\ jcabrera@iies-unah.org \\ María Auxiliadora López Méndez, Universidad Nacional Autónoma de Honduras (UNAH), \\ Facultad de Ciencias Económicas, Administrativas y Contables (FCEAC), \\ Instituto de Investigaciones Económicas y Sociales (IIES), \\ Ciudad universitaria, edificio C2, primer piso, Tel/fax: (504) 2239-1849 \\ mlopez@iies-unah.org
}

Revista Economía y Administración (E\&A)

\begin{abstract}
This paper analyzes the competitiveness of exports from Honduras to United States, Western Europe and CACM. In turn, the paper is divided into five sections: the first section briefly describes various theories of international trade as well as some ways to measure international competitiveness in exports of nations. The second section explains the methodology of the CAN, and software TradeCAN 2012 and MagicPlus. The third, fourth and fifth section describes and analyzes the CAN exports from the perspective of the top ten products exported from Honduras to the markets mentioned in the 1990-2010 period except United States where the period is expanded until 2012, determining the competitive type (Rising Star, Moon Star, Withdrawn, Lost Opportunity) of such goods in different periods of analysis.
\end{abstract}

Keywords: CAN, Exports, Rising Star, Moon Star, Withdrawn, Lost Opportunity 


\section{INTRODUCCIÓN}

En 2011, según la Organización Mundial del Comercio (WTO) el flujo comercial de la economía mundial registró un crecimiento cercano $5 \%$ respecto a 2010. Para el mismo periodo el flujo de las exportaciones y las importaciones hondureñas crecieron $5.27 \%$ y $4.82 \%$ respectivamente teniendo como principales socios comerciales Estados Unidos, Unión Europea y Mercado Común Centro Americano (MCCA), estos mercados representaron $40.5 \%$ del total de mercancías exportadas por Honduras (Banco Central de Honduras,2012). Entre las 99 secciones que se divide a 2 dígitos según la Clasificación Uniforme de Comercio Internacional (CUCI), se observa que las mercancías del capítulo 61 (Prendas y complementos de vestir, de punto) y las del capítulo 09 (Café, té, yerba mate y especias) son las de mayor participación en las exportaciones de Honduras para 2012. Aunque las tasas del crecimiento de las exportaciones hondureñas se han mantenido a la alza estas tuvieron un sustancial descenso en el 2009, viéndose afectado gran parte de los sectores exportadores. Es de destacar que Honduras en la última década ha tenido un grado de apertura al comercio exterior CONSIDERABLE, para 2012 y 2011 el grado de apertura fue 118 y 121 correspondientemente, este alto grado de apertura se traduce en que Honduras es un país altamente dependiente de la actividad del comercio internacional.

El presente trabajo tiene como objetivo principal elaborar un análisis de las exportaciones de mercancías de Honduras hacia los mercados de Norteamérica y Europea Occidental desde la perspectiva de la metodología CAN en el periodo 1990-2012, a su vez se describe en qué consiste la metodología CAN (Competitive Analysis of Nations) en su versión 2012, de igual forma se utilizará los softwares derivados de la metodología CAN; el software MagicPlus y el TradeCAN 2012, ambos desarrollados por la Comisión Económica para América Latina y el Caribe (CEPAL). En el estudio se describe las principales mercancías de exportación por parte de Honduras así como la situación de estas en los demás países del MCCA (Guatemala, Nicaragua, El Salvador y Costa Rica). Partiendo de ello se determinará cuáles son los principales países rivales de Honduras en materia de exportación hacia los mercados previamente mencionados y de igual forma se determinará las mercancías de mayor dinamismo en el comercio mundial. 
Revista

Economía y Administración (E\&A)

\section{ASPECTOS TEÓRICOS SOBRE LA COMPETITIVIDAD DE LAS NACIONES}

Al hablar de competitividad de los países lo primero que sobresale para muchos es el estudio realizado por el World Economic Forum (WEF) o Foro Económico Mundial este se encarga de medir en un ranking de competitividad a los países, este se basa en el estudio de cuatro factores principales; el desempeño económico, la eficiencia gubernamental, eficiencia empresarial e infraestructura, a su vez estos cuatro factores agrupan 114 variables divididas en doce pilares, de esta manera la WEF pondera un índice llamado The Global Competitiveness, Reporte en el cual ordena a los países en un ranking en el que Honduras para el informe 20132014 se ubicó en el lugar 111 de 148 posibles, esto indica que Honduras está en un lugar no muy predilecto es decir poco competitivo (World Economic Forum, 2013). Si bien esta herramienta elaborada por el WEF resulta ser útil, recibe la crítica de pecar de subjetividad en la medición de algunas de sus variables, además resulta compleja su estimación por lo que hace poco práctico darle un seguimiento a su medición.

Si bien Honduras no podría competir en materia de exportación con algunos de sus productos frente a países que tienen una ventaja absoluta, es decir países que producen más y que poseen mayor cantidad de insumos (tierra, cantidad de trabajadores, capital), existe un término llamado "ventaja comparativa" este concepto establece que un país podrá competir ante cualquier otro país que posea ventaja absoluta siempre y cuando tenga una ventaja comparativa, es decir, que este país se especialice en productos que le sea relativamente más barato producir un bien, además de lo anterior, Heckscher y Ohlin postulan que las naciones exportarán los bienes en los que su factor intensivo (trabajo o capital) sea abundante y barato en el país, e importara los bienes donde el factor de producción sea escaso y costoso (Krugman y Obstfeld, 2006).

Otros aportes al entendimiento de la competitividad la realiza Porter (1990) en su artículo "The Competitive Advantages of Nations" menciona que la base de la competitividad es la producción de las empresas, y que una alta productividad le ayudará a disminuir sus costos, y por ende ser más competitivo. No obstante Krugman (1994) argumenta que la competitividad de un país dista mucho de la manera en que las empresas enfrentan y mejoran su competitividad. En términos más sencillos se puede analizar 
la competitividad entre países mediante el Índice del Tipo de Cambio Real Efectivo (ITCRE), donde la conjetura principal consta en que la depreciación de la moneda nacional disminuye la competitividad del país, y en caso contrario una apreciación de la moneda generará una ganancia en la competitividad internacional, además de ello el efecto inflacionario conllevará una ponderación en el cálculo del ITCRE. Aunque el ITCRE resulta ser una herramienta muy útil para analizar la competitividad de los países, este resulta estar limitado por dos aspectos, el primero de ellos es que está altamente influenciado por el año base elegido, y el otro es que no guarda relación alguna con criterios de productividad, tecnología e innovación (Bonifaz y Mortimore, 1999).

\section{METOdología DEL CAN COMO HERRAMIENTA DE ANÁLISIS DEL COMERCIO EXTERIOR}

La metodología CAN surge con la idea de Ousmene J. Mandeng en 1991 con el artículo "Competitividad internacional y especialización”. A su vez el CAN cuenta con un software llamado TradeCAN 2012 que facilita el desarrollo del análisis del comercio internacional desde esta perspectiva, el TradeCAN incorpora la información de 73 países que representan más del $90 \%$ del flujo comercial mundial. Los datos son obtenidos de International

Revista Economía y Administración (E\&A) Commodity Trade Database (COMTRADE) de las Naciones Unidas y los datos están organizados acorde a las secciones de la clasificación Uniforme para el Comercio Internacional (CUCI) expresadas en dólares corrientes de Estados Unidos, usando el valor de costo. El TradeCAN 2012 cuenta con una base de datos del periodo 1985 hasta 2010, es de destacar que todos los años se refieren al promedio central de una serie de tres años. Es decir, por ejemplo 1995 representa, el promedio del flujo comercial del trienio \{1994, 1995 y 1996$\}$, a su vez 1996 será la media de los años \{1995, 1996 y 1997$\}$. La ventaja de trabajar de esta manera es que se descartan las fluctuaciones cíclicas de muy corto plazo (CEPAL, 2012).

Los criterios en los cuales se basa el CAN son los siguientes:

a. Cuota de mercado. Es el valor de las exportaciones del sector $i$ desde al país A al mercado importador B, como porcentaje del valor total de las importaciones del sector $i$ en el mercado B. 
b. Porcentaje de exportaciones. El valor de las exportaciones del sector $i$ desde el país A hacia el país importador B, como un porcentaje del total de las exportaciones del país A al mercado B.

c. Especialización. Compara la cuota de mercado de un país A para el sector $i$ con la cuota de mercado total del país A. si la participación de mercado del sector es mayor que la participación de mercado total, se dice que el país A está especializado en el sector $i$, Si es menor, se dice que el país A no está especializado en el sector $i$.

d. Porcentaje de importaciones. El valor de las importaciones del sector $i$ en el mercado importador expresado como un porcentaje del valor total de las importaciones del mercado B.

e. Participación del rival. Compara la cuota de mercado del país A con la cuota de mercado del país R. (CEPAL, 2012; P14).

Revista Economía y Administración (E\&A)

Asimismo, la metodología CAN ubica la competitividad internacional de las exportaciones de las naciones en cuatro categorías a las que se denominan tipologías, estas son: Estrellas Menguantes, Estrellas Nacientes, Retiradas y Oportunidades Perdidas. Cuando un producto se le denomina Estrella Menguante ello simboliza que este producto está en una situación de vulnerabilidad, denota que el país está siendo competitivo en sectores estancados del comercio internacional. En el caso de las Estrellas Nacientes estas denotan los sectores dinámicos del comercio internacional en los cuales aumenta la participación de mercado del país exportador y aumenta la demanda del producto por parte del país importador, este es el punto en el cual un país tiene sus exportaciones en situación competitiva y es el punto donde desean ubicar sus productos exportados los países. Una Oportunidad Perdida, indica los sectores dinámicos del comercio internacional donde las exportaciones del país disminuyen su participación en el mercado del país importador. Retiradas revelan los sectores donde el país pierde participación de mercado y a su vez estos sectores se encuentran en situación de estancamiento, es decir son mercados en decadencia. Estas cuatro denotaciones son representadas en una matriz esta se le da el nombre de "matriz de competitividad" gráficamente la matriz se representa de la siguiente manera: 


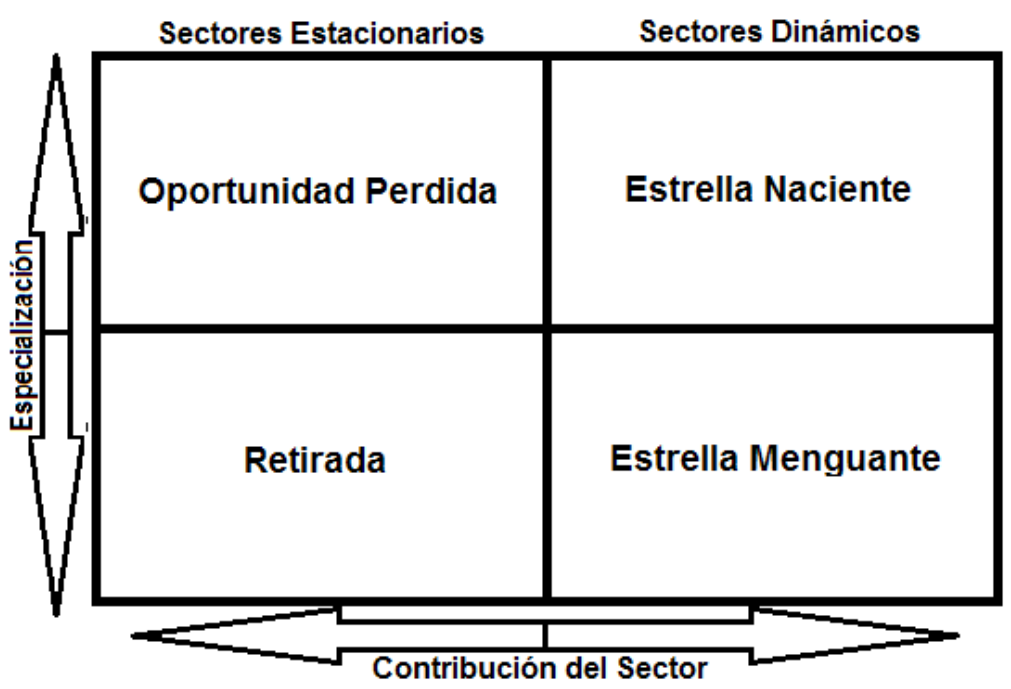

Figura No. 1 Matriz de Competitividad

Revista

Economía y Administración $(E \& A)$

Un país pretende que la mayoría de sus exportaciones (si no es que todas) se sitúen en el cuadrante I (Estrellas Nacientes) ya que se entiende que es la situación óptima de la competitividad internacional, y también pretenderá que ninguno de sus productos se ubique en la tipología de Retirada.

A pesar de ser una de las herramientas más dinámicas en la actualidad Bonifaz y Mortimore (1999) al igual que pasa con el ITCRE y con el Anuario de Competitividad Mundial detectan diversas limitaciones en el CAN, por ejemplo no permite identificar las distorsiones económicas que suscitan a lo interior de los países, y tampoco detecta las exportaciones cuyo contenido nacional es bajo, es decir países que tienen Zonas Industriales de Procesamiento (ZIP) como principal estrategia de exportación.

Derivado de la metodología CAN está el programa computacional TradeCAN, este para su versión 2012 cuenta con una serie de datos extraída de la base oficial del comercio internacional mantenida por la oficina de Estadística de las Naciones Unidas (COMTRADE) dichos datos son valores en dólares corrientes americanos y aglutina 73 países que representan el $90 \%$ del flujo total del comercio mundial, a su vez el TradeCAN para el ordenamiento de los productos utiliza la Clasificación Uniforme para el Comercio Internacional (CUCI Rev. 2). 
La importancia del mercado estadounidense se refleja en que la CEPAL desarrolló un software para analizar su comercio con el resto del mundo, dicho software se deriva de la metodología CAN y recibe el nombre de MagicPlus y a diferencia del TradeCAN 2012, el MagicPlus si cuenta con una serie estadística actualizada a 2012, otra gran diferencia es la nomenclatura utilizada por ambos software, es decir el TradeCAN se enmarca en CUCI Rev. 2, mientras que el MagicPlus utiliza el CUCI pero en su revisión 4, a pesar de lo mencionado, ambos softwares poseen la misma finalidad, esta consiste en analizar las cualidades del comercio exterior con sus diferentes tipologías de competitividad.

\section{EVOLUCIÓN DE LAS EXPORTACIONES DE HONDURAS}

Revista Economía y Administración (E\&A)
A partir del año 1990 el comercio exterior pasó a ser de gran importancia ya que su participación en el PIB real a partir del 1990 aumentó progresivamente, pasó de 4\% en 1990 hasta alcanzar un máximo de $56.1 \%$ en 2006 y para 2010 disminuyó a $45.8 \%$. El grado de apertura de Honduras medible a través de la suma del comercio exterior (importaciones más exportaciones) dividida entre el PIB, resultó ser de 109.5 para 2010 y para 2012 este indicador se posicionó en 118.4, es decir, Honduras es un país totalmente abierto al comercio exterior, es de resaltar que para 1990 dicho grado de apertura era de 47.8 lo que convertía a Honduras en un país medianamente abierto al comercio exterior.

Las exportaciones reales de Honduras para el año 2010 fueron de 73,135.4 millones de Lempiras esto representó 45.8\% del PIB real, teniendo un incremento de $19.8 \%$ respecto a 2009 , aunque dicho incremento fue significativo esto no alcanzó los niveles observados en 2008 (81,160.7 millones de lempiras), es de destacar que 2009 fue un año donde se observó los efectos de la crisis financiera mundial suscitada en 2008, para el caso de Honduras el PIB real disminuyó $2.4 \%$ y las exportaciones tuvieron un impacto aún más sustancial disminuyendo $24.4 \%$ en referencia a 2008 , tal efecto se explica debido a que la crisis financiera afecto en mayor medida al principal socio comercial de Honduras (Estados Unidos). 1999 es un año que merece una mención especial, el fenómeno climático Mitch ocurrido en octubre de 1998 generó que en 1999 las exportaciones disminuyeran levemente en $0.7 \%$. 


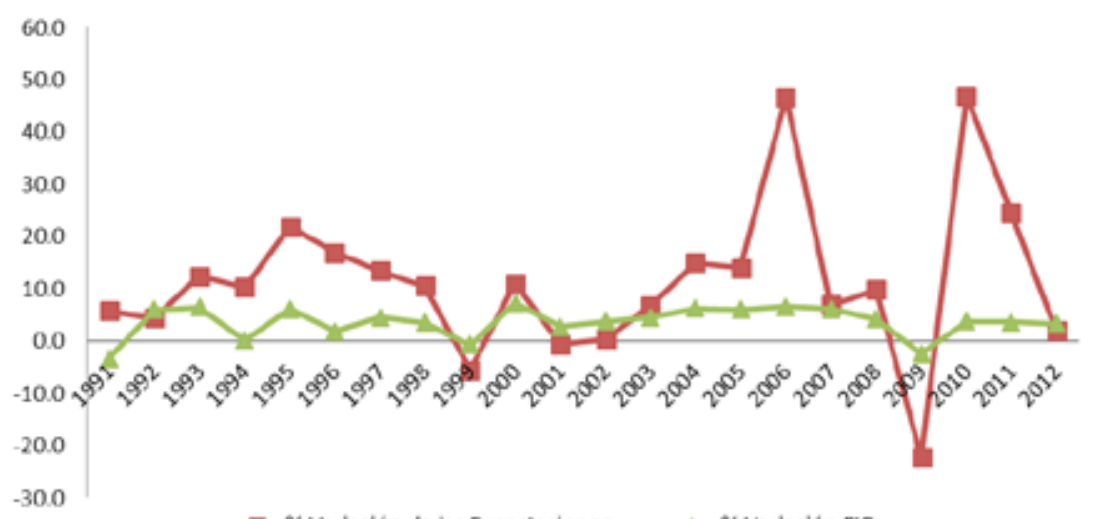

- $\%$ Variación de las Exportaciones $\quad-$ W Variación PIB

Figura No. 2 Honduras: Variación porcentual de las exportaciones y el PIB (Precios Reales 2000=100) año 1991-2012

Fuente: Elaboración propia con datos del Banco Central de Honduras

\subsection{DESTINO DE LAS EXPORTACIONES HONDUREÑAS}

Según el Banco Central de Honduras, Estados Unidos de América es el principal socio comercial de Honduras, dicho país en el año 2012 recibió $34 \%$ de las exportaciones de Honduras, sin embargo, esta participación en el mercado de Estados Unidos fue mayor en 2009 representando 39\%, no obstante, fue menor en valores absolutos debido a la caída del comercio exterior hondureño en 2009, si sumamos a Canadá el porcentaje de exportaciones hondureñas en 2012 hacia Norteamérica alcanza el 35.2\%. El segundo receptor de mercancías hondureñas es el mercado europeo con una participación del $25 \%$ para 2010 , es destacar que ambos mercados tienen una composición distinta, el mercado norteamericano importa principalmente productos manufacturados, a diferencia de Europa donde predomina el café, sin embargo este apartado lo abordaremos en la sección 4 y 5 del estudio. El tercer socio comercial de Honduras en materia de exportaciones es el Mercado Común Centroamericano (MCCA), es decir, Guatemala, Nicaragua, El Salvador y Costa Rica, con una importación del $18.5 \%$ de los productos exportados por Honduras para 2012. Estos tres mercados Norteamérica, Europa y MCCA, además de ser los principales socios comerciales por el flujo de mercancías, también los podemos considerar como los socios naturales de Honduras teniendo en cuenta la cercanía geográfica y los tratados comerciales que se han establecido con estos Bloques.

Revista Economía y Administración (E\&A) 
Es de agregar que la composición de dichos socios comerciales no ha variado en la última década, para el año 2000 Norteamérica era el primer comprador de las mercancías hondureñas con $45.8 \%$ de participación del total, Europa con $23 \%$ y MCCA con $20 \%$ ocuparon segundo y tercer lugar respectivamente. (Ver figura No. 1,2 y 3).
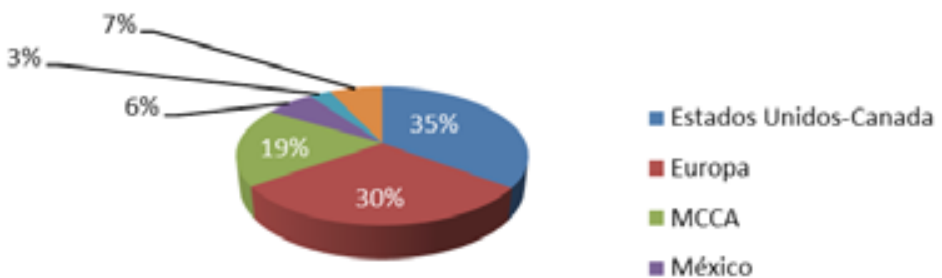

Figura No. 3 Destino de las exportaciones de Honduras, año 2012

Fuente: Elaboración propia con datos del Banco Central de Honduras

Revista Economía y Administración (E\&A)

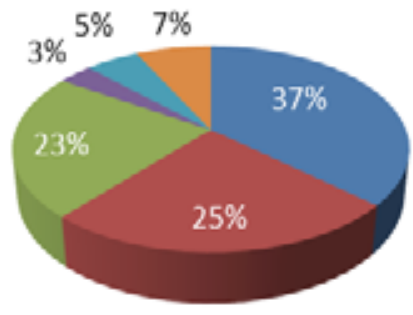

- Estados Unidos-Canada

Europa

I MCCA

" México

nesto de Latinoamerica

Figura No. 4 Destino de las Exportaciones de Honduras, año 2010

Fuente: Elaboración propia con datos del Banco Central de Honduras

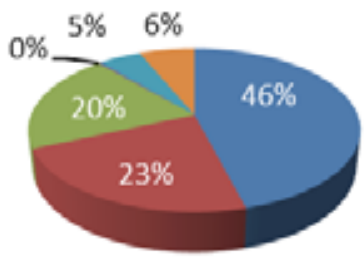

= Estados Unidos-Canada
= Europa
m MCCA
= México
m Resto de Latinoamerica

Figura No. 5 Destino de las exportaciones de Honduras, año 2000

Fuente: Elaboración propia con datos del Banco Central de Honduras 


\section{HONDURAS EN EL MERCADO DE ESTADOS UNIDOS}

Estados Unidos es el principal mercado para el comercio exterior de Honduras, para el año 2012 este mercado importaba 34\% de las mercancías hondureñas. En esta sección se determina la competitividad de los principales productos de Honduras en este mercado utilizando la metodología CAN y el software MagicPlus, de igual forma se establece los diez principales productos hondureños por participación en este mercado.

El principal producto hondureño en el mercado de Estados Unidos son la Prendas y Complementos de Vestir (Cap. 61), este producto para el año 2012 representó $46.2 \%$ del total exportado hacia este mercado, seguidamente se encuentra las Prendas y Complementos de Vestir Excepto los de Punto (Capitulo 62 de la Clasificación Uniforme para el Comercio Internacional) con $10.8 \%$ de participación para el mismo año, cabe destacar que ambos productos se derivan de la sección de prendas de vestir y accesorios, la misma composición se observó en el año 2000 donde estos productos predominaron. No obstante para el año 1990 los productos derivados de las prendas de vestir tenían una representación relativamente baja (cap. $616.38 \%$ y Cap. 62 16.5\%) considerando que Honduras para dicho año orientaba sus exportaciones hacia los productos animales y vegetales, tal es así que frutas y frutos comestibles (Cap.08) representaban su principal producto de exportación con una participación del 31.9\%. sin embargo según Interiano (s.f.) la promulgación del Decreto No. 3787 del 7 de Abril de 1987, incentivó el auge de la industria manufacturera (maquila) en Honduras y es a partir de los años 90's cuando la estructura de las exportaciones de Honduras hacia Estados Unidos comienza a cambiar y a ser orientada primordialmente hacía los productos de la maquila, hasta convertirse en las principales mercancías de exportación. (Ver Tabla No. 1).

Revista Economía y Administración (E\&A) 
Tabla No. 1

Honduras: Diez Principales exportaciones por contribución hacia Estados Unidos (en porcentajes)

Revista Economía y Administración (E\&A)

\begin{tabular}{|c|c|c|c|c|}
\hline Productos/ periodo & 1991 & 2000 & 2010 & 2012 \\
\hline GI Prendas y Camplementas de Vestir, de Punto & 6.38 & 54.7 & 51.88 & 46.2 \\
\hline 62 Prendas y Complementas de Vestir, Excepto los de Punto & 16.55 & 23.5 & 11.12 & 10.8 \\
\hline 85 Máquinas, Aparatos y Material Eléctrico y sus Partes & प & 2.28 & 9.02 & 11.4 \\
\hline 08 Frutas y Frutas Comestibles: Cortezas de Agrias (Cítricas) & 31.95 & 3.56 & 5.61 & 5.56 \\
\hline प9 Café Té, Yerba Mate y Especias & 9.48 & 3.19 & 2 & 6.II \\
\hline 71 Perlas Finas Naturales (a cultivadas) , Piedras preciosas & 0.01 & 0.3 & 4.5 & 4.56 \\
\hline $\begin{array}{l}03 \text { Pescadas y Crustáceas, Moluscas y Demás Invertebradas } \\
\text { Acuáticas }\end{array}$ & 12.55 & 4.16 & 4.51 & 3.74 \\
\hline $\begin{array}{l}87 \text { Vehículos Autamóviles, Tractores, Velocípedos, Demás } \\
\text { vehículos y sus partes }\end{array}$ & 0 & 0.39 & 1.7 & 1.68 \\
\hline 98 Formas y Esbozos, Рага Botones & 0.96 & 1.18 & 2.97 & 1.79 \\
\hline Z4 Tabaca y Sucedáneas del Tabaca, Elaboradas & 2.93 & 1.92 & 1.79 & 1.78 \\
\hline
\end{tabular}

Fuente: Elaboración propia en base al software MagicPlus 2012, CEPAL

En la tabla No. 1 se observa las diez principales mercancías de exportación de Honduras hacia Estados Unidos, destacando que para el 2012 las prendas de vestir derivadas del capítulo CUCI 61 y 62 así como los productos del capítulo 71, 85 y 87 se encuentran entre los 20 principales productos importados por Estados Unidos en 2012 resaltando que son mercancías producto de la industria manufacturera (maquila).

\subsection{TIPOLOGÍA DE LAS PRINCIPALES EXPORTACIONES DE HONDURAS HACIA ESTADOS UNIDOS}

El software MagicPlus 2012 permite realizar el análisis de la competitividad de las exportaciones a un nivel de desagregación de dos dígitos CUCI (Tabla No. 2). 
Tabla No. 2

\section{Honduras: Matriz de competitividad de las principales exportaciones en el mercado de Estados Unidos}

\begin{tabular}{|c|c|c|c|c|}
\hline Productas/perioda & 1991 & 2000 & 2010 & 2012 \\
\hline $\begin{array}{l}\text { Gl Prendas y Complementos de } \\
\text { Vestir, de Punto }\end{array}$ & $\begin{array}{l}\text { Estrella } \\
\text { Naciente }\end{array}$ & $\begin{array}{c}\text { Estrella } \\
\text { Menguante }\end{array}$ & $\begin{array}{l}\text { Estrella } \\
\text { Menguante }\end{array}$ & Retirada \\
\hline $\begin{array}{l}62 \text { Prendas y Complementos } \\
\text { de Vestir, Excepto los de Punto }\end{array}$ & $\begin{array}{l}\text { Estrella } \\
\text { Naciente }\end{array}$ & Retirada & Retirada & $\begin{array}{c}\text { Estrella } \\
\text { Menguante }\end{array}$ \\
\hline $\begin{array}{l}85 \text { Máquinas, Aparatos, } \\
\text { Material Eléctrica y sus Partes }\end{array}$ & $\begin{array}{l}\text { Estrella } \\
\text { Naciente }\end{array}$ & $\begin{array}{l}\text { Estrella } \\
\text { Naciente }\end{array}$ & $\begin{array}{l}\text { Estrella } \\
\text { Menguante }\end{array}$ & $\begin{array}{l}\text { Estrella } \\
\text { Naciente }\end{array}$ \\
\hline $\begin{array}{l}08 \text { Frutas y Frutas } \\
\text { Camestibles: Cortezas de } \\
\text { Agrios (Cítricos) } \\
\end{array}$ & $\begin{array}{l}\text { Oportunidad } \\
\text { Perdida }\end{array}$ & $\begin{array}{c}\text { Estrella } \\
\text { Menguante }\end{array}$ & Retirada & $\begin{array}{l}\text { Estrella } \\
\text { Naciente }\end{array}$ \\
\hline $\begin{array}{l}09 \text { Café Té, Yerba Mate y } \\
\text { Especias }\end{array}$ & $\begin{array}{l}\text { Oportunidad } \\
\text { Perdida }\end{array}$ & $\begin{array}{c}\text { Estrella } \\
\text { Menguante }\end{array}$ & Retirada & $\begin{array}{c}\text { Estrella } \\
\text { Menguante }\end{array}$ \\
\hline $\begin{array}{l}\text { 71 Perlas Finas Naturales ( } \\
\text { cultivadas) , Piedras preciosas }\end{array}$ & $\begin{array}{l}\text { Estrella } \\
\text { Naciente }\end{array}$ & $\begin{array}{l}\text { Estrella } \\
\text { Naciente }\end{array}$ & $\begin{array}{l}\text { Oportunidad } \\
\text { Perdida }\end{array}$ & $\begin{array}{c}\text { Estrella } \\
\text { Menguante }\end{array}$ \\
\hline $\begin{array}{l}03 \text { Pescados y Crustáceos, } \\
\text { Moluscas y Demás } \\
\text { Invertebrados Acuáticas }\end{array}$ & $\begin{array}{l}\text { Estrella } \\
\text { Naciente }\end{array}$ & $\begin{array}{c}\text { Estrella } \\
\text { Menguante }\end{array}$ & $\begin{array}{l}\text { Estrella } \\
\text { Menguante }\end{array}$ & Retirada \\
\hline $\begin{array}{l}87 \text { Vehículos Autamóviles, } \\
\text { Tractores, Velocípedos y } \\
\text { Demás vehículos, sus Partes y } \\
\text { Accesorios }\end{array}$ & No Definida & $\begin{array}{l}\text { Estrella } \\
\text { Menguante }\end{array}$ & $\begin{array}{l}\text { Estrella } \\
\text { Naciente }\end{array}$ & $\begin{array}{l}\text { Opartunidad } \\
\text { Perdida }\end{array}$ \\
\hline $\begin{array}{l}\text { 乌o Formas y Esbozos, Рага } \\
\text { Botones }\end{array}$ & $\begin{array}{l}\text { Estrella } \\
\text { Menguante }\end{array}$ & Retirada & $\begin{array}{l}\text { Estrella } \\
\text { Menguante }\end{array}$ & $\begin{array}{l}\text { Oportunidad } \\
\text { Perdida }\end{array}$ \\
\hline $\begin{array}{l}24 \text { Tabaco y Sucedáneos del } \\
\text { Tabaco, Elaborados }\end{array}$ & $\begin{array}{l}\text { Oportunidad } \\
\text { Perdida }\end{array}$ & $\begin{array}{c}\text { Estrella } \\
\text { Menguante }\end{array}$ & Retirada & $\begin{array}{l}\text { Oportunidad } \\
\text { Perdida }\end{array}$ \\
\hline
\end{tabular}

Revista

Economía y Administración $(E \& A)$

Fuente: Elaboración propia en base al software MagicPlus 2012, CEPAL 
Revista

Economía y

Administración

(E\&A)

\section{HONDURAS EN EL MERCADO DE EUROPA OCCIDENTAL}

El software TradeCAN agrupa como mercado importador a los países de Europa Occidental es por ello que en esta sección se utiliza el término Europa Occidental más como un agregado de países que como un bloque económico diferenciándolo de la Unión Europea, en dicha agrupación el TradeCAN incluye los siguientes países: Alemania, Austria, Bélgica y Luxemburgo, Dinamarca, España, Finlandia, Francia (incluido Martinica, Mónaco, Guadalupe y Reunión), Grecia, Islandia, Irlanda, Italia, Noruega, Suiza y Liechtenstein, Países Bajos, Portugal, Suecia y Reino Unido.

El mercado europeo es el segundo socio comercial de Honduras, para el año 2012 este recibía el 30\% del total de las mercancías hondureñas. Al igual que en la sección 4 en este apartado se establece la competitividad de los principales productos de Honduras en el mercado de Europa Occidental utilizando la metodología CAN, de igual forma se determina los diez principales productos hondureños por participación en este mercado.

Para el año 2010 el producto que lideró las exportaciones hondureñas en el mercado europeo fue el café y sucedáneos del café (071 CUCI) con una predomínate participación de $61.8 \%$ en cuanto al segundo lugar este lo ocupó las frutas y nueces (057 CUCI) representado el 9\%, de igual forma el café lideró las exportaciones hondureñas en el año 2000, sin embargo esto fue distinto en 1990 donde Honduras orientó su comercio hacia las frutas y nueces con un peso de $47.6 \%$, sin dejar de lado el café que para ese entonces tenía una representación de $25.4 \%$. Otros productos a destacar aunque con menor medida para el año 2010 son los crustáceos y moluscos pelados (036 CUCI) y los aceites fijos de origen vegetal (424 CUCI) con una representación de $5.3 \%$ y $4.6 \%$ respectivamente. 
En la tabla No. 3 se observa los diez principales productos a tres dígitos de desagregación CUCI de exportación de Honduras hacia el mercado de Europa Occidental, a pesar de que el café es el producto predominante en este mercado, dicho producto no sobresale entre los 50 productos de mayor flujo a nivel mundial, si destacan las frutas y nueces, la ropa interior de punto y la ropa exterior y accesorios de vestir.

Tabla No. 3

\section{Honduras: Participación porcentual de los diez principales productos de exportación hacia Europa Occidental.}

\begin{tabular}{|c|c|c|c|}
\hline Productos/ Años & 1990 & 2000 & 2010 \\
\hline 071 Café y sucedáneos del café & 25.4 & 46.2 & 61.8 \\
\hline 057 Frutas y nueces (exc. nueces oleaginosas) frescas a secas & 47.6 & 27.3 & 8.9 \\
\hline 036 Crustáceos y moluscos pelados o sin pelar & 2.5 & 5.8 & 5.3 \\
\hline 424 Dtros aceites fijos de origen vegetal & 0.4 & 0.5 & 4.6 \\
\hline 846 Ropa interiar de punto o ganchilla & 1.1 & 2.9 & 4.3 \\
\hline 845 Ropa exterior y accesorios de vestir de punto o ganchillo & 0.07 & 0.8 & 3 \\
\hline Q377 Pescados, crustáceas y moluscos, prep. o en conserva & 0 & 0.2 & 2.2 \\
\hline 292 Productos vegetales en bruto & 1.6 & 1.7 & 1.6 \\
\hline 287 Minerales de metales comunes y sus concentrados & 8.7 & 3.4 & 1.4 \\
\hline DEl Azúcar y miel & 0 & 0.01 & 1.4 \\
\hline
\end{tabular}

Fuente: Elaboración propia mediante la información del software TradeCAN2012

\subsection{TIPOLOGÍA DE LAS PRINCIPALES EXPORTACIONES DE HONDURAS HACIA EUROPA OCCIDENTAL.}

La matriz de competitividad de las principales exportaciones de Honduras hacia el mercado europeo a dos dígitos CUCI Rev. 2 descrita en la tabla No. 4 destaca cinco productos en la tipología de Estrella Naciente. Debido a su importancia y participación en el mercado europeo es de resaltar el Café, té, cacao, especias y sus preparados $(057 \mathrm{CUCI})$ el cual obtiene la categoría de estrella naciente para el 2010, año que coincide con su mayor porcentaje de participación. Aunque en los años 1990 y 2000 el café aumentaba su participación en el mercado europeo, este producto resultó ser una Retirada, explicado según la metodología CAN a que el mercado europeo 
no demandada este producto en misma proporción a la que Honduras incrementaba la exportación de café.

Las prendas de vestir (84 CUCI) aunque con una menor participación el mercado europeo en comparación al café, es de resaltar dado que estas mercancías figuran en los tres mercados de estudio, representan por tanto una Estrella Naciente. El segundo producto de importancia para Honduras teniendo en cuenta su participación en el mercado europeo son las legumbres y frutas, para el año 2010 estos productos obtuvieron la tipología de Oportunidad Perdida, esto se explica debido a la disminución que tuvo Honduras en la exportación de dichos productos.

Tabla No. 4

\section{Honduras: Matriz de competitividad de los principales productos en Europa Occidental}

Revista Economía y Administración (E\&A)

\begin{tabular}{|c|c|c|c|}
\hline Producto/ Año & 1990 & 2000 & 2010 \\
\hline $\begin{array}{l}\text { 03 Pescado, crustácens y moluscas y sus } \\
\text { preparados }\end{array}$ & $\begin{array}{l}\text { Estrella } \\
\text { Naciente }\end{array}$ & Retirada & $\begin{array}{l}\text { Estrella } \\
\text { Naciente }\end{array}$ \\
\hline 84 Prendas de vestir y sus accesorios & $\begin{array}{l}\text { Estrella } \\
\text { Naciente }\end{array}$ & $\begin{array}{l}\text { Estrella } \\
\text { Menguante }\end{array}$ & $\begin{array}{l}\text { Estrella } \\
\text { Naciente }\end{array}$ \\
\hline $\begin{array}{l}28 \text { Menas y desperdicios y desechas de } \\
\text { metales }\end{array}$ & $\begin{array}{l}\text { Estrella } \\
\text { Menguante }\end{array}$ & Retirada & $\begin{array}{l}\text { Estrella } \\
\text { Menguante }\end{array}$ \\
\hline 05 Legumbres y frutas & $\begin{array}{l}\text { Oportunidad } \\
\text { Perdida }\end{array}$ & Retirada & $\begin{array}{l}\text { Oportunidad } \\
\text { Perdida }\end{array}$ \\
\hline O6 Azúcar, ргерагаdos de azúcar y miel & $\begin{array}{l}\text { Oportunidad } \\
\text { Perdida }\end{array}$ & Retirada & $\begin{array}{l}\text { Estrella } \\
\text { Naciente }\end{array}$ \\
\hline 42 Aceites y grasas fijos de origen vegetal & $\begin{array}{l}\text { Oportunidad } \\
\text { Perdida }\end{array}$ & $\begin{array}{l}\text { Estrella } \\
\text { Menguante }\end{array}$ & $\begin{array}{c}\text { Estrella } \\
\text { Menguante }\end{array}$ \\
\hline $\begin{array}{l}\text { 77 Café, té, cacau, especias y sus } \\
\text { preparados }\end{array}$ & Retirada & Retirada & $\begin{array}{l}\text { Estrella } \\
\text { Naciente }\end{array}$ \\
\hline $\begin{array}{l}\text { 29 Productos animales y vegetales en } \\
\text { bruto }\end{array}$ & Retirada & $\begin{array}{l}\text { Estrella } \\
\text { Menguante }\end{array}$ & $\begin{array}{l}\text { Estrella } \\
\text { Naciente }\end{array}$ \\
\hline
\end{tabular}

Fuente: Software TradeCAN2012 dos digitos Rev. 2 CUCI, CEPAL. 


\section{HONDURAS EN EL MERCADO COMÚN CENTROAMERICANO (MCCA)}

En esta sección se analiza la competencia de las exportaciones hondureñas hacia MCCA utilizando el software TradeCAN. Cabe destacar que el tercer bloque económico de importancia comercial para Honduras es el MCCA (Guatemala, El Salvador, Nicaragua y Costa Rica), mismo en el cual Honduras está contenida y por lo cual es entendible el flujo comercial que se da entre los países de esta zona. Según BCH para 2012 los países del MCCA recibían 19\% de las exportaciones hondureñas, 4.3\% menos que el 2010 y $1.4 \%$ menos que el año 2000, esto como respuesta al aumento del flujo comercial que Honduras ha experimentado con los países del continente europeo sobre todo con los productos derivados del café.

Para 2010 a tres dígitos (CUCI Rev. 2) el principal producto hondureño exportado hacia el MCCA fue el gas natural y artificial (341 CUCI) con una participación del 13.2\% del total exportado de Honduras en este mercado, diez años antes este producto no era de mucho importancia para el comercio exterior hondureño, dado que representó apenas $0.79 \%$ y para 1990 era inexistente. La ropa interior de puto y de ganchillo (846 CUCI) figura como el segundo producto de exportación de Honduras hacia el MCCA, representa el $9.4 \%$ y $1.28 \%$ para 2010 y 2000 respectivamente. El tercer producto con

Revista Economía y Administración $(E \& A)$ mayor participación son los otros aceites fijos de origen vegetal (424 CUCI) en esta sección del CUCI se encuentran productos derivados de la palma africana, mismo que ha tenido un auge en la economía hondureña de la última década, y para 2010 representó $8.68 \%$ de lo exportado por Honduras hacia el MCCA. El cuarto producto de importancia, si se tiene en cuenta la participación en este mercado, es el jabón y preparados para limpiar y pulir (554 CUCI) que para el año 2000 lideraba las exportaciones hondureñas en MCCA, con una participación de $16.13 \%$, sin embargo para 2010 dicha participación disminuyó 9.5 puntos porcentuales. 
Tabla No. 5

\section{Honduras: Participación porcentual de los diez principales productos de exportación hacia el MCCA}

Revista Economía y Administración (E\&A)

\begin{tabular}{|c|c|c|c|}
\hline Producto / Año & 1990 & 2000 & 2010 \\
\hline 341 Gas natural y artificial & 0 & 0.79 & 13.19 \\
\hline 846 Ropa interior de punto o ganchilla & 1.07 & 1.28 & 9.4 \\
\hline 424 Dtros aceites fijos de origen vegetal & 4.92 & 7.2 & 8.68 \\
\hline 554 Jabón y ргерагаdos para limpiar y pulir & 7.76 & 16.13 & 6.63 \\
\hline 655 Tejidos de punto a ganchilla & 0.03 & 0.16 & 4.8 \\
\hline I22 Tabaco manufacturado & 0 & 5.73 & 4.49 \\
\hline 893 Artículas de las materias descritas en el cap. 58 & 1.59 & 1.67 & 4.47 \\
\hline $\begin{array}{l}\text { G42 Papeles y cartones recortados en forma } \\
\text { determinada }\end{array}$ & 3.24 & 2.42 & 3.6 \\
\hline 048 Preparados de cereales y de harina fina & 1.13 & 0.94 & 3.35 \\
\hline 08ا Piensos para animales (excepto cereales sin moler) & 0.22 & 0.35 & 2.61 \\
\hline
\end{tabular}

Fuente: Software TradeCAN2012 dos digitos Rev. 2 CUCI, CEPAL.

\subsection{TIPOLOGÍA DE LAS PRINCIPALES EXPORTACIONES DE HONDURAS HACIA EL MCCA.}

La matriz de competitividad de las principales exportaciones de Honduras hacia el MCCA a tres dígitos CUCI Rev. 2 descrita en la tabla No. 5 destaca tres productos en la tipología de Estrella Naciente, es decir en un contexto competitivo. El Gas natural y artificial pese a que se sitúa en el primer lugar de las exportaciones hondureñas hacia el MCCA, este producto resultó ser una Oportunidad Perdida en el año 2010, misma tipología obtuvo en el año 2000 y en 1990 se estableció como "No Definido" debido a que para ese año la exportación hondureña de dicho producto, fue inexistente. Al igual que en el mercado de Estados Unidos, la ropa interior de punto o ganchillo se ubicó como una Estrella Menguante para el año 2000 y 2010, la principal razón de ello es que Guatemala, Nicaragua y El Salvador han entrado en la competencia del mercado de las prendas de vestir en la primer década del milenio, por lo tanto han dejado de demandar dichos productos. Por otro lado el jabón y preparados para limpiar y pulir (554 CUCI) representaron en 1990 el primer producto hondureño en el MCCA y para el mismo año la tipología 
competitiva de este producto fue una Estrella Menguante, no obstante para el año 2000 este producto alcanzó 16.1\% de las exportaciones hacia el MCCA logrando ubicarse en la situación predilecta de Estrella Naciente, para el 2010 el jabón adquirió la tipología de Oportunidad Perdida lo que significa que Honduras perdió participación en un mercado rentable. A pesar de ocupar el octavo, noveno y décimo lugar de la lista para el año 2010, los papeles y cartones recortados (642 CUCI), los preparados de cereales (048 CUCI) y los piensos para animales (081 CUCI), obtuvieron la tipología de Estrella Naciente lo que significa que los mencionados productos están adquiriendo mercado en el MCCA y aumentando su participación en las exportaciones de Honduras. También es de resaltar que los piensos para animales, la ropa interior se encuentran entre los 50 productos más comercializados a nivel mundial.

Tabla No. 6

\section{Matriz de competitividad de los principales productos hondureños en el MCCA}

\begin{tabular}{|c|c|c|c|}
\hline Producto / Año & 1990 & 2000 & 2010 \\
\hline 341 Gas natural y artificial & No Definido & $\begin{array}{l}\text { Oportunidad } \\
\text { Perdida }\end{array}$ & $\begin{array}{l}\text { Oportunidad } \\
\text { Perdida }\end{array}$ \\
\hline 846 Ropa interior de punto a ganchilla & $\begin{array}{l}\text { Oportunidad } \\
\text { Perdida }\end{array}$ & $\begin{array}{c}\text { Estrella } \\
\text { Menguante }\end{array}$ & Estrella Menguante \\
\hline 424 Dtros aceites fijos de origen vegetal & Retirada & Retirada & $\begin{array}{l}\text { Oportunidad } \\
\text { Perdida }\end{array}$ \\
\hline 554 Jabón y preparados para limpiar y pulir & $\begin{array}{l}\text { Estrella } \\
\text { Menguante }\end{array}$ & Estrella Naciente & $\begin{array}{l}\text { Dpartunidad } \\
\text { Perdida }\end{array}$ \\
\hline 655 Tejidas de punto o ganchilla & $\begin{array}{l}\text { Estrella } \\
\text { Naciente }\end{array}$ & $\begin{array}{l}\text { Estrella } \\
\text { Menguante }\end{array}$ & Retirada \\
\hline I22 Tabaco manufacturado & Retirada & Estrella Naciente & $\begin{array}{l}\text { Oportunidad } \\
\text { Perdida }\end{array}$ \\
\hline $\begin{array}{l}893 \text { Artículos de las materias descritas en el } \\
\text { cap. } 58\end{array}$ & $\begin{array}{l}\text { Estrella } \\
\text { Naciente }\end{array}$ & $\begin{array}{l}\text { Oportunidad } \\
\text { Perdida }\end{array}$ & $\begin{array}{l}\text { Opartunidad } \\
\text { Perdida }\end{array}$ \\
\hline $\begin{array}{l}642 \text { Papeles y cartones recortados en forma } \\
\text { determinada }\end{array}$ & $\begin{array}{l}\text { Estrella } \\
\text { Menguante }\end{array}$ & $\begin{array}{l}\text { Oportunidad } \\
\text { Perdida }\end{array}$ & Estrella Naciente \\
\hline 048 Preparados de cereales y de harina fina & $\begin{array}{l}\text { Estrella } \\
\text { Naciente }\end{array}$ & Estrella Naciente & Estrella Naciente \\
\hline $\begin{array}{l}\text { 081 Piensas para animales (excepto cereales } \\
\text { sin maler) }\end{array}$ & $\begin{array}{l}\text { Estrella } \\
\text { Naciente }\end{array}$ & $\begin{array}{l}\text { Dportunidad } \\
\text { Perdida }\end{array}$ & Estrella Naciente \\
\hline
\end{tabular}

Revista Economía y Administración $(E \& A)$ 


\section{CONCLUSIONES}

- Las exportaciones de Honduras difieren según el mercado receptor, mientras que Estados Unidos importa más los artículos de la maquila, Europa se interesa por los productos primarios o agrícolas.

- El TradeCAN versión 2012 resulta ser una herramienta útil en el análisis de la competencia de los países en el comercio exterior, su metodología da una noción en promedio acertada del estado de la competitividad de las mercancías en un periodo determinado.

- A pesar de que el TradeCAN utilizado en el estudio es la versión 2012 no ofrece información a dicho año, limitando el análisis a dos años de rezago es decir al año 2010, induce a meramente realizar un análisis retrospectivo de la competitividad de las exportaciones hondureñas, dejando para estudios posteriores el poder obtener una noción del comportamiento de las exportaciones a largo plazo.

- El Café y sucedáneos del café (057 CUCI) son el principal producto de exportación de Honduras hacia Europa Occidental representando el $61.8 \%$ del total para el año 2010. En el mercado de Estados Unidos el producto con mayor participación son las Prendas y Complementos de

Revista Economía y Administración (E\&A) Vestir, de Punto (Cap. 61) con $46.2 \%$ de participación, es de destacar que las prendas de vestir figuran entre los diez principales productos en ambos mercados.

- Los productos que lideran las exportaciones hondureñas en los mercados del MCCA y Estados Unidos no obtuvieron la tipología de Estrella Naciente, lo cual hace notar que Honduras con su principal producto en estos mercados estaba siendo competitivo en mercados estancados que tienden a disminuir su demanda. Caso contrario paso con el mercado europeo donde el café está en la situación óptima de competitividad.

- A diferencia de Europa y Estados Unidos donde las exportaciones hondureñas son lideradas por uno y dos sectores, el MCCA tiene un mercado más diversificado, es decir la participación de los productos hondureños en el MCCA. 


\section{REFERENCIAS BIBLIOGRÁFICAS}

Banco Central de Honduras (2013). Memoria Anual 2012. Recuperado el 1 de Julio de 2013, de http://www.bch.hn/memoria_anual.php

Comisión Económica para América Latina y el Caribe (s.f.). Manual de usuario TradeCAN 2012.

Dussel, E. (2001). Un análisis de la competitividad de las exportaciones de prendas de vestir de Centroamérica utilizando los programas y la metodología CAN y MAGIC. Publicación de las Naciones Unidas. Estudios y perspectivas, 1. Recuperado el 5 de julio de 2013 de http://www.eclac.org/cgi-bin/getProd. asp?xml=/publicaciones $/ \mathrm{xml} / 8 / 9888 / \mathrm{P} 9888 . \mathrm{xml} \& \mathrm{xsl}=/ \mathrm{mexico} / \mathrm{tpl} / \mathrm{p} 9 f$. $\mathrm{xsl} \&$ base $=/ \mathrm{mexico} / \mathrm{tpl} /$ top-bottom.xsl

Interiano, J. (s.f.). Historia de la maquila en Honduras. Recuperado el 9 de julio de 2013, de http:/www.ahm-honduras.com/wp-content/uploads/2011/08/ historia-maquila-honduras.pdf

Krugman, P. y Obstfeld, M. (2006). Economía Internacional Teoría y Política (7ª ed.). Madrid: Pearson.

Krugman, P. (1994). Competitiveness: Adangerous Obsession. Foreign Affairs, 73 (2), 28-44. Recuperado el 17 de Julio de 2013, de http://www.jstor. org/Discover $/ 10.2307 / 20045917$ ?uid=3738192\&uid=2\&uid=4\&s $\mathrm{id}=21102473932111$

Organización Mundial del Comercio (2012). Acerca del Comercio Internacional. Recuperado el 14 de septiembre de 2013, de http:// wto.org/spanish/news_s/pres12_s/pr658 s.htm

Porter, M. (1990). The Competitive Advantages of Nations. Harvard Buisness Review, 90211, 7491. Recuperado el 16 de Julio de 2013, de http://hbr.org/ product/competitive-advantage-of-nations/an/90211-PDF-ENG

World Economic Forum (2013). The Global Competitiveness Report 20132014. Recuperado el 18 de diciembre de 2013 de http://www.weforum.org/ reports/global-competitiveness-report-2013-2014

Este artículo fue seleccionado de trabajos presentados en la Primera Conferencia Internacional sobre Economía, Administración y Tecnología, evento organizado por el Consorcio Economía, Administración y Tecnología (CEAT). El documento original ha seguido el proceso de revisión estándar de la Revista Economía y Administración (E\&A). El proceso fue dirigido por el Ing. Marvin Aguilar (CEAT-2013) y supervisado por el PhD. Jorge Flores Silva, MSc. Manuel Flores Fonseca y PhD. Jesús Argueta Moreno (Editores de E\&A). 